\title{
Elementos para uma espiritualidade do diälogo inter-religioso
}

Recebido: 03/08/2016. Aprovado: 31/08/2016.

\author{
Elias Wolff*
}

Resumo: O termo "espiritualidade" tem um universo semântico eminentemente plural, o que o caracteriza como algo dinâmico e inerente à existência de indivíduos e grupos. No interior do mundo multirreligioso existem tensões e conflitos entre as tradições religiosas e espirituais que não poucas vezes desequilibram o complexo social. Nosso objetivo é, nesse contexto, refletir sobre as possibilidades de um encontro entre as espiritualidades, enquanto propostas de sentido para a existência humana e do planeta, como base para o encontro das tradições religiosas. É a partir do "diálogo espiritual" que os contrastes teóricos e práticos das religiões podem ser trabalhados no sentido de favorecer-lhes uma fecundação recíproca pelo mútuo conhecimento e acolhida, o intercâmbio e a cooperação.

Palavras-chave: Espiritualidade. Mística. Religião. Diálogo.

Abstract: The concept of "spirituality" has an eminently plural semantic universe, which characterizes it as something dynamic and inherent to the existence of individuals and groups. In the inside of the multi-religious world there are tensions and conflicts among the religious and spiritual traditions that, not seldom, unbalance the social complex. Our purpose, in this context, is to ponder about the possibilities of an encounter among the spiritualities, as valid proposals of meaning for the existence of mankind and of the planet, as a basis to the encounter among the religious traditions. Departing from the "spiritual dialog", the theoretical and practical contrasts among the religions may be confronted with the aim of favoring their reciprocal fecundation through the mutual knowledge and welcome, interchange and cooperation.

Keywords: Spirituality. Mystic. Religion. Dialogue.

* Doutor em Teologia, Pontifícia Universidade Gregoriana, Roma. Membro do Programa de Pós-graduação, Pontifícia Universidade Católica do Paraná - PUCPR, Curitiba, PR. Bolsista Produtividade CNPq. 


\section{Introdução}

O termo "espiritualidade" tem um significado eminentemente plural em sua origem etimológica e em seu universo semântico. Essa pluralidade caracteriza a sua natureza como algo dinâmico e inerente à existência de indivíduos e grupos, expressando a diversidade religiosa do nosso tempo. A compreensão dessa realidade apresenta dificuldades devido à complexidade e multiplicidade de formas e conteúdos historicamente construídos nas diversas culturas. No interior do mundo multirreligioso existem tensões e conflitos entre as tradições religiosas e espirituais, que não poucas vezes desequilibram o complexo social, mesmo nas sociedades que afirmam os valores da democracia, igualdade, liberdade. Nosso objetivo aqui é refletir sobre as possibilidades de um encontro entre as espiritualidades enquanto propostas de sentido para a existência humana e do planeta, como base para o encontro das tradições religiosas. Entendemos que as religiões dificilmente se encontram em suas doutrinas, seus mitos, seus ritos, seu ethos. Mas podem encontrar-se "no espírito" que anima esses elementos. Nossa tese é que somente onde isso for possível pode-se pensar num diálogo inter-religioso fecundo.

\section{O contexto religioso da atualidade}

A partir do final do século XIX, o avanço da civilização técnicocientífica, o racionalismo e a secularização na organização da vida social, tornaram-se bases de uma sociedade que se pretende auto-suficente em relação à religião, possibilitando que no século $\mathrm{XX}$ se intensificassem as teses sobre o desaparecimento da religião (H.G. Cox). Muitos afirmaram um "eclipse de Deus" (M. Buber), a "falta de Deus" (M. Heidegger), a "morte de Deus" (T.J.J. Altizer), o "ocultamento de Deus" (J. Sudbrack) ou sua "distância" (K. Rahner).

Contudo, o mundo pós-moderno não apenas não eliminou a religião, como previam essas teorias, mas, pelo contrário, possibilitou o seu reflorescer e com uma diversidade impressionante. Tal diversidade se expressa tanto no interior das religiões tradicionais quanto pelo surgimento de novos movimentos religiosos. E se configura com as características da cultura pós-moderna como a intuição, a emoção, a liberdade, a subjetividade, a individualidade, a fragmentação, entre outras. Nesse contexto, ao lado das instituições religiosas tradicionais, há um comportamento religioso individual e comunitário que prescinde das formalidades das 
religiões tradicionais. Religião se vive como crença pessoal ou grupal, não necessariamente com vínculo institucional. Há religiões mais ou menos institucionalizadas, há religião sem instituição e há crença sem religião. O contexto social favorece mais a adesão de uma proposta espiritual com as características da cultura atual do que a adesão aos sistemas religiosos tradicionais (WOLFF, 2016, p. 23-36).

Isso não acontece sem tensões, dentre as quais:

1) Crise do papel social da religião: a religião não é mediação dos vínculos entre os crentes, pois a fé é uma questão individual e privada. Ela não mais contribui, como outrora, para a organização e a unidade da vida humana e social. A cultura do contingente, do imediato, do pragmático fragmentou a realidade. Diante do múltiplo, o uno ficou impensável; diante da diferença, perdeu-se a relação e a convergência. A verdade é singular, individual, local. Assim é também a vivência religiosa.

2) Tensão entre religião e fé: existe hoje uma profunda crise da religião enquanto mediação institucional necessária da expressão de fé. Fé e religião se distinguem, mas historicamente se implicam mutuamente sendo a religião a formalização do conteúdo da fé. Em nossos dias, porém, a fé se expressa sem religião alguma. A instituição religiosa deixou de ser mediação necessária na relação da pessoa com o divino, do mundo com um Criador, do natural com o sobrenatural.

3) Conflitos religiosos: crescem as manifestações de tensão e de conflitos por motivos religiosos. Isso acontece, inclusive, nas sociedades com ares de democracia, valorização da diversidade e afirmação da tolerância. Posturas fundamentalistas, exclusivistas e absolutistas na vivência religiosa promovem, aqui e acolá, atitudes de intolerância, discriminação e preconceito por motivos de fé. Grupos religiosos tradicionais e novos movimentos religiosos concorrem de forma agressiva na conquista do espaço social.

É nesse contexto que urge favorecer o encontro, o diálogo e a cooperação entre as religiões. Contribuem para isso as pesquisas sobre religião nas diferentes áreas da ciência, possibilitando que teólogos e líderes religiosos possam reconhecer um significado positivo nas doutrinas, nos mitos, nos ritos, nos símbolos, na ética da religião do outro. O intercâmbio dos valores místicos e espirituais dos sistemas religiosos é uma questão chave para o encontro e interação entre eles. 


\section{Distinção semântica de religião e espiritualidade}

Há uma distinção a ser feita entre religião e espiritualidade. Toda religião é ou tem também uma espiritualidade, mas nem toda espiritualidade tem ou é uma religião. Por espiritualidade entendemos algo dinâmico e circunscrito à existência de cada indivíduo e cada comunidade humana. É a expressão do espírito de uma pessoa ou grupo, suas motivações, seus ideais, suas utopias (MARIA VIGIL; CASALDÁLIGA, 1996, p. 22-26). Essa expressão pode acontecer tanto na dimensão humana - como a forma de uma pessoa cultivar o seu espírito, dando consistência ao horizonte de sentido de sua própria vida; quanto na dimensão religiosa - como o fundamento e o significado sobrenatural da vida, alimentado por crenças e ritos religiosos. A religião é uma expressão da dimensão espiritual do humano, ela capta o espírito humano em suas diferentes manifestações ao mesmo tempo que possibilita a expressão dessas manifestações em ritos, doutrinas e mitos. Assim, não pode haver religião que satisfaça ao ser humano sem uma espiritualidade correspondente. A espiritualidade é o coração da religião, seu sangue e sua energia vital, enquanto a religião é o corpo que dá forma à espiritualidade.

Não se trata de opor religião à espiritualidade, mas de entender que há uma distinção entre ambas. Enquanto a religião aponta para o aspecto externo da vida do crente, o ato ritualístico, cúltico, a espiritualidade mostra a sua interioridade e também a sua transcendência. E o dado espiritual é mais amplo que o religioso. O espírito pode ter muitas formas de manifestação, religiosa ou não. $O$ desafio para a religião é fazer um redimensionamento espiritual que possibilite assegurar o seu lugar no espaço social atual, que pode não simpatizar com "religião", mas manifesta aberturas para a "espiritualidade" que ela propõe.

\section{O triunfo espiritual do nosso tempo}

A afirmação da sociedade moderna não significou a derrota da religião, mas a crise do seu papel social tradicional. Outrora, a religião contribuía para a integração da vida humana e social, interferindo nas relações que se dão no complexo social. Atualmente, a sociedade prescinde da religião para se organizar.

A sociedade pós-moderna pode não buscar a religião, mas convive com ela, ou pelo menos a tolera, desde que não haja interferência do religioso na autonomia do social. E a cultura da pós-modernidade dá as condições simbólicas para a religião reorganizar-se, o que não é sem 
ambiguidades e perigos para a religião. De um lado, a religião não terá plausibilidades de penetração e reconhecimento na cultura atual sem entrar na estrutura da mentalidade, da linguagem, do simbólico dessa cultura. De outro lado, a religião não pode ficar à mercê da cultura, precisa sustentar-se em sua própria origem, natureza e fim. O conteúdo religioso não é meramente cultural, mesmo se o são a sua formulação e expressão. Daqui a importância de a religião manter um distanciamento crítico em relação à cultura. A questão fundamental é redescobrir o papel da religião na sociedade que agora não mais se organiza religiosamente:

O que importa agora pensar é a existência de crentes numa sociedade estruturada sem dependência de deuses e não mais querer retroceder a uma luta agressiva entre dois poderes, luta que não existe mais, porque não há mundo fora da modernidade e esta não se define mais simplesmente contra os valores da fé (ARAÚJO DE OLIVEIRA, 2013, p. 87).

Se a atual sociedade não demonstra simpatia para com as religiões tradicionais, no entanto manifesta-se aberta para os movimentos de espiritualidade que emergem, tanto do interior das religiões tradicionais, quanto fora delas. Não significa que a modernidade assuma a espiritualidade como algo que lhe seja necessário. Mas o paradoxo é que as correntes de espiritualidade que surgem hoje aparecem como resultado do momento sócio-cultural moderno. As religiosidades e espiritualidades contemporâneas têm uma configuração própria desse tempo. Elas servemse das condições da modernidade para criar ou recriar significados que buscam atender o indivíduo em sua subjetividade e individualidade. $\mathrm{O}$ mundo social, objetivo, é desencantado, organiza-se como um espaço autônomo a toda religião ou espiritualidade. Mas permite que o mundo pessoal, subjetivo, continue aberto para o mistério, o invisível, o inefável. Daqui porque as novas religiosidades e espiritualidades têm hoje mais acolhida do que as religiões tradicionais.

\section{Passos para o encontro das religiões}

Como entender o lugar e a função das diferentes religiões na sociedade atual? Primeiramente, possibilitando um entendimento comum entre elas. Esse entendimento comum supõe um espaço também comum no qual as diferentes religiões se situem. Assim, é preciso entender o pluralismo religioso e espiritual atual não como um problema, mas como expressão do direito à liberdade de consciência e de religião dos cidadãos. As religiões e 
as espiritualidades se entenderão entre si na medida em que os seus membros se entenderem como portadores de direitos iguais no meio social. $\mathrm{O}$ desafio consiste em renunciar a toda pretensão de exclusividade ou monopólio na interpretação e configuração do sentido da realidade sócio-humana. Cada crente precisa relacionar suas convicções de fé com outras convicções, sejam elas religiosas ou não. As religiões e as espiritualidades podem promover relações interpessoais que estabeleçam uma "intersubjetividade igualitária e diversa” (ARAÚJO DE OLIVEIRA, 2013, p. 107).

O segundo passo, a partir do direito de existir de cada religião e cada espiritualidade, é buscar contribuir com a sociedade. A sociedade não é um campo de batalha espiritual, mas um espaço de encontro e cooperação entre as religiosidades e espiritualidades. As religiões a as espiritualidades têm a capacidade de captar as necessidades mais profundas e existenciais do ser humano, como a paz, a segurança, o desenvolvimento integral, a afirmação da liberdade e da dignidade, a promoção da vida... E muito podem contribuir para que a sociedade proporcione aos cidadãos as condições para isso. As propostas das religiões e espiritualidades não devem ser formuladas exclusivamente a partir de si mesmas, de suas doutrinas e visões de mundo, mas a partir também do que pode ser de fato comum para o conjunto da sociedade. É preciso buscar o bem comum sem sacrificar as próprias convicções, mas sacrificando, se necessário for, os interesses próprios. Talvez seja necessária, em alguns casos, a reconfiguração radical da visão de mundo e das ações. O espírito democrático deve imperar no espírito da liberdade que cada um busca para si e que precisa, na mesma medida, assegurar para o outro. Trata-se do exercício da solidariedade na convivência social, favorecendo para a criação de estruturas e instituições que lhe deem sustentabilidade. Essas estruturas devem ser capazes de garantir a igualdade entre todos, a liberdade e a dignidade humana, a defesa da vida no planeta. As convicções de fé devem levar as pessoas a sentirem-se responsáveis pelas situações que causam dor e sofrimento na humanidade atual.

O terceiro passo é o diálogo sobre os elementos de convergência e de divergência entre as diferentes religiões e espiritualidades. "Diálogo" é expressão do espírito vital (ruah, pneuma, spiritus), de algo que tem vida. Tudo o que tem vida "res-pira", o que pode ser entendido como tudo o que tem vida dialoga. De um lado, o diálogo tem a força e a energia dos sujeitos do diálogo. De outro lado, o diálogo é comunicante de vitalidade aos dialogantes, ou seja de uma espiritualidade. Temos aqui o encontro das espiritualidades e a "espiritualidade do diálogo" como troca, intercâmbio, interação, comunhão de universos de significados existenciais 
diferentes. O diálogo é, então, o ato de exteriorizar a interioridade e interiorizar outras exterioridades (WOLFF, 2016, p. 18-19).

O quarto passo é o intercâmbio espiritual. A interioridade humana mais profunda é configurada pelas crenças religiosas. Essas buscam manter vivo o sentido maior e último da existência que está para além da própria existência - o Outro, o Infinito, a Realidade Última, o Espírito Absoluto... Deus. A religião é vivida numa "economia sacramental", ou seja, com elementos concretos e visíveis que possibilitam e expressam a relação com o Invisível, numa experiência espiritual como experiência de salvação que invade a história e a vida humanas.

\section{Elementos mediadores do encontro espiritual das religiões}

Desenvolveremos aqui o terceiro e quarto passos para o encontro de religiões e espiritualidades, destacando três elementos centrais para todas. O encontro nesses elementos é chave para o diálogo entre as grandes tradições religiosas da humanidade.

\subsection{A experiência espiritual}

As diferentes espiritualidades possibilitam aos crentes uma experiência fundante e fundamental do sentido da vida, mas com formas antagônicas. Não há uma compreensão única de espiritualidade em sua natureza, meios e fins. Isto é motivo de tensões, conflitos e desencontros entre as religiões. Esses desencontros estão sustentados e se expressam no elemento fundamental e específico que configura uma experiência religiosa.

Mas é possível verificar também convergências entre essas diferenças. A experiência espiritual acontece no contexto das experiências humanas, pois "a experiência religiosa dá-se na experiência geral; elas podem ser diferenciadas, mas não separadas" (TILLICH, 1967, p. 738). A espiritualidade relaciona dois âmbitos, do humano e do divino; do "profano" e do "sagrado/santo". Na espiritualidade, esses dois âmbitos interferem-se mutuamente. A tensão dessa interferência é apaziguada na profundidade da comunhão mística com o Mistério, que acontece em tempos e lugares particulares, através de palavras e objetos sacramentais, alimentada nos ritos que buscam obter do Sagrado o "mais" que a humanidade necessita. 
Não é nos seus elementos externos, mas na "essência" da experiência que está a possibilidade de encontro das diferentes experiências religiosas. A experiência religiosa profunda é uma experiência mística, como encontro com o numinoso, que se caracteriza pelo temor, a reverência, o mistério, o estupor; é uma experiência mística que se expressa pela sensação de paz, serenidade, alegria, comunhão; é uma experiência de totalização das demais experiências, que sintetiza a história pessoal dando-lhe um sentido global. Essa experiência coloca a pessoa diante de um ser ou objeto extraordinário, revestido de poder total. A vida humana passa a depender dessa força transcendente, descoberta em algo ou alguém, compreendido como divino, sagrado, santo. Isto é verificável em toda experiência religiosa, com as devidas peculiaridades na prática e na formulação. Mas a experiência do Ilimitado não se limita a nenhuma religião, a nenhum lugar sagrado, a nenhuma ação sagrada particular. Quando uma experiência particular do divino tenta identificar-se com ele, começam os fundamentalismos, exclusivismos e conflitos entre as religiões.

Para todos os crentes, o objeto da experiência religiosa é, portanto, o Mistério, a Realidade Última, o que dá sentido. É isso que move o espírito de uma pessoa ou grupo religioso. Religião é vivência espiritual como um "estado de experiência de um valor absoluto" (TILLICH, 1968, p. 95), vivência expressada de diferentes formas nos símbolos, mitos, ritos, figuras, mediações, das diferentes religiões: "Qualquer que seja o contexto histórico no qual esteja imerso, o homo religiosus acredita sempre que exista uma realidade absoluta, o sagrado, que transcende este mundo, mas que se manifesta nele e, por isso mesmo, santifica-o e o faz real" (ELIADE, 1995, p. 170).

\subsection{A meta da experiência espiritual}

A espiritualidade visa qualificar a existência do crente, o que implica em mudança de vida, transformação. Ele passa de um estado de menos perfeito para um mais perfeito, no sentido pessoal, social e religioso. Busca-se a supressão das necessidades de toda ordem física, psíquica, sócio-cultural por uma relação com a realidade que está acima e ao mesmo tempo no mais profundo do humano. As limitações são superadas na experiência espiritual passando do fragmentário ao totalizador, do finito ao infinito, da falta de sentido à esperança utópica. Para isso contribuem os ritos cúlticos, especialmente os de iniciação, de sacrifício e de purificação. No final, vive-se uma experiência de libertação/salvação, 
como realização plena do eu pessoal imerso na realidade sobrenatural. Essa realidade acontece na medida em que a pessoa sente que a experiência religiosa respondeu, de fato, "aos enigmas recônditos da condição humana, que ontem como hoje comovem o seu coração" (NA 1).

Cada tradição religiosa possibilita essa experiência com o seu próprio significado como mito/meta, fim salvífico. Nas religiões mistéricas do antigo Oriente Médio e da Grécia, o significado maior é a realização plena que acontece como revelação dos conhecimentos secretos que dão sabedoria e, por esta, a salvação (V. FERM, 1965, p. 171-191); no Advaita Vedanta, busca-se encarnar o Brahman, o Absoluto de toda realidade; no dharma e no sangha busca-se a iluminação como a "condição de buda", um genuíno sentido de transcendência pelo que se alcança o nirvana. A meta do judaísmo, cristianismo e islamismo é o Reino no qual se tem a realização plena do espírito humano. Salvas as diferenças de natureza da meta última da religiosidade, num sentido geral podemos dizer que esta meta é alcançar "libertação/salvação" como objetivo e cume da vida humana e religiosa: "não há experiência religiosa que ignore o desejo de salvação" (CROATTO, 2001, p. 46).

É difícil, se não impossível, alcançar uma sintonia com o cristianismo sobre a natureza teológica da meta última das diferentes religiões - que aqui designamos com o conceito geral de "libertação/salvação". A principal aproximação talvez esteja na concepção bíblica do "Reino de Deus" (DHAVAMONY, 1998, p. 174-189.206-207)'. Algumas religiões o entendem num sentido espiritual sobrenatural, que possibilita a visão direta do divino ${ }^{2}$. Outras o entendem num sentido apenas humano/ético, como um código de religião e de moralidade que orienta a conduta humana no cumprimento do seu dever para com Deus, consigo mesmo e com a sociedade ${ }^{3}$. A diferença fundamental é que enquanto em algumas

1 Ver também: FARQUAHR, J. N. Modern Religious Movements in India. New York: The Macmillan \& Company, 1918; PRABHAVANANDA, Swami. The Sermon on the Mount according to Vedanta. New York: Mentor Book, 1972; CARUS, P. The Gospel of Buddha. Nova Delhi: Government of India, 1969; MURRAY, T. Islam and the Kingdom of God. Princeton, 1933.

2 Há representações do hinduísmo que entendem dessa forma a proposta cristã do Reino, como a organização Ramakrishna Mission Swamis, para quem o Reino de Deus tende à realização da identidade de todos os seres com o Absoluto.

3 RAM MOHAN ROY. The Precepts of Jesus, The Guide to Peace and Happiness. Citado por DHAVAMONY, M., 1998, p. 178. Nesse sentido está o entendimento comum sobre Cristo no hinduísmo, como apenas um modelo a ser imitado. O seu ensinamento é "uma íntima fé espiritual na realização da consciência da unicidade da humanidade, baseada na consciência da unicidade de Deus, que assinala o bem-estar universal" (DHAVAMONY, 1998, p. 180). 
religiões aquilo que poderia ser a experiência do Reino é buscada pelo próprio esforço (a pacificação no nirvana, a iluminação na condição de Buda), para o cristão o Reino acontece por uma iniciativa gratuita de Deus em Cristo. O cristão já tem a "posse" do Reino pela fé em Cristo, pode experimentá-lo na própria história pelo encontro com o Cristo encarnado e a vivência da fé e da caridade ${ }^{4}$. Isso, porque Cristo é para os cristãos Deus na terra, e não apenas uma mediação humana que orienta a prática da justiça e o comportamento moral. Assim, o Reino de Deus manifesta-se na terra pela pessoa mesma do Cristo.

A ideia cristã do Reino é assimilada nas religiões a partir de suas perspectivas próprias. Nem tudo é convergência, naturalmente, mas um cristão pode ver ali sinais do Reino no qual ele acredita: "Os homens esperam das diversas religiões a resposta aos enigmas recônditos da condição humana, que hoje como ontem comovem intimamente seu coração" (NA 1). Nesse sentido, merecem ser valorizadas "todas as ideias que proponham um reino celeste transcendente ... ou um reino interior de experiência religiosa ... ou um reino político consistente em uma nova ordem social" (DHAVAMONY, 1998, p. 189).

\subsection{A mediação}

A vivência espiritual acontece por elementos mediadores da relação entre o humano e o divino. Cada espiritualidade emprega os meios que julga em harmonia com o tipo de experiência suprema que propõe. Algumas concebem uma divindade suprema intocável e divindades intermediárias para o contato com o mundo. Há divindades cósmicas intermédias, que governam e cuidam do mundo, há divindades que atuam através de ritos e sacrifícios, e há pessoas que servem de mediação entre o divino e o humano.

O que permite algo ou alguém cumprir o papel de mediador na relação entre o humano e o divino é a experiência espiritual que ele realizou e que, como conseqüência, possibilita realizar. Surgem, assim, espiritualidades específicas a partir da experiência que alguém faz do Espírito. É o que acontece com Krishna, Buda, Jesus Cristo, Maomé ... Evidentemente, são notórias as diferenças na identidade de cada um, no conteúdo da experiência feita e que permite fazer. $\mathrm{O}$ que queremos ressaltar é que esses mediadores

4 Para aprofundar a relação entre o ensinamento de Cristo e o de Buda, ver SUZUKI, 1971. 
realizaram uma especial e incomum experiência espiritual, que os torna reveladores do sentido da vida de quem os segue.

Que relação é possível estabelecer entre os líderes espirituais das religiões e Jesus Cristo no papel de mediador entre a humanidade e a divindade? Em que medida essa relação questiona ou está em sintonia com a pretensão de unicidade e universalidade da mediação de Cristo (At 4,12; 1Tm 2,3-5; Jo 14,6)?

O hinduísmo não nega, em princípio, a possibilidade de Jesus ser uma encarnação divina do Brahman, pois não há apenas um avatar como manifestação definitiva da divindade5. Um budista pode considerar Jesus Cristo como um bodhisattva, isto é, um líder religioso asceta que ajuda a viver o dharma e a iluminação da própria existência; e um muçulmano o vê como um profeta. Para os cristãos, porém, isso é pouco. Na fé cristã, Jesus Cristo é o "único Filho de Deus" encarnado (Jo 1,14), com uma ação eterna e universal de reconciliação do mundo com Deus (2 Cor $5,19)$. Ele foi por Deus constituído como "Senhor e Cristo" através de sua morte na cruz e ressurreição (At 2,36), pelo que se tornou o único mediador entre Deus e a humanidade (At 4,12; 1 Tm 2,3-5; Jo 14,6).

A teologia das religiões propõe dois caminhos para uma compreensão cristã do papel dos líderes espirituais das religiões. O primeiro é identificar a presença de Cristo nas diferentes religiões. Tudo o que possibilita uma verdadeira experiência de Deus, o faz n'Aquele que habita em todas as coisas que existem (Sb 11,24-12,1). Toda verdadeira oração é feita no Espírito que ora em nós. Assim, Deus, que falou ao mundo através do Filho, falou também "de muitos outros modos e de muitas outras maneiras" (Hb 1,1). Não poderia estar falando também através das diferentes religiões, sobretudo das mais tradicionais na história da humanidade? Pois o Verbo habitou em Jesus (Jo 1,14), mas a Sabedoria

5 Há duas compreensões disso. No contexto advaita a aparição da divindade é ilusória, não tangível; mas o hinduísmo tem também uma expressão monoteísta, na qual admite aparições da divindade em forma visível, o avatar, mantendo a distinção entre o Deus pessoal e a realidade individual de quem o recebe. Assim é com Krishna, que mantém uma distinção substancial entre a divindade e a humanidade. O avataré teofânico, com distintas formas e graus de aparição de Deus, em diferentes pessoas (DHAVAMONY, 1998, p. 147). Tentou-se uma relação com o hinduísmo entendendo que "Cristo nasceu nas profundidades do espírito". Sua vida, morte e ressurreição são "processos universais da vida espiritual, que se cumprem continuamente na alma dos homens" (MACDERMOTT, 1976, p. 293). Em relação a Krishna, tentou-se entender o evento Cristo como uma "conquista da alma, como uma gloriosa iluminação interior na qual a sabedoria divina se converte em herança da alma" (MACDERMOTT, 1976, p. 293). 
já estava presente em todos os povos e nações (Eclo 24,6-7). Não é o espírito das religiões expressão do Espírito que conduz todos ao mistério pascal nos modos que só Deus conhece (GS 22)? Pois,

se o evento-Cristo é o sacramento universal da vontade de Deus de salvar o gênero humano, não é preciso para isso que ele seja a sua única expressão possivel. O poder salvífico de Deus não está ligado exclusivamente ao sinal universal que ele projetou para sua ação salvifica... O mistério da encarnação é único; tão somente a existência individual de Jesus foi assumida pelo Filho de Deus. Contudo, se apenas ele foi constituído desse modo como 'imagem de Deus', também outras 'figuras salvificas'... podem ser 'iluminadas'pelo Verbo ou 'inspiradas'pelo Espírito para se tornarem indicadores de salvação para seus fiéis, de acordo com o plano abrangente de Deus para a humanidade (DUPUIS, 1997, p. 412-413).

Isso não nega a unicidade da mediação de Jesus Cristo na realização do plano salvífico de Deus. Mas entende uma "unicidade complementar", ou melhor, "unicidade relacional", no sentido que o evento Cristo não é absolutizado de modo fechado e isolado do pluralismo religioso, mas é entendido "dentro da totalidade das expressões religiosas" (BRETON, 1981, p. 149-159). Jesus Cristo tem, assim, uma "unicidade constitutiva: nele, a particularidade histórica, coincide um significado universal" do plano salvífico de Deus (DUPUIS, 1997, p. 420). Assim entendendo, "O encontro entre as fés deve ajudar os cristãos a descobrirem novas dimensões no testemunho que Deus deu de si mesmo nas outras comunidades de fé" (DUPUIS, 1997, p. 407).

O segundo caminho é aproximar os meios utilizados pelos mediadores da relação do ser humano com Deus. A cruz, por exemplo, é rejeitada por hindus, budistas, judeus e muçulmanos. Mas não é impossível uma aproximação da verdade cristã sobre a cruz e a morte do ego proposta pelo budismo (SUZUKI, p. 101-103). A aproximação com o islamismo estaria no fato de a cruz de Cristo significar total submissão à vontade de Deus. Mas permanece a divergência entre o que é esforço humano para libertação na meditação budista, e a ação da graça divina no cristianismo; bem como a diferença entre o realismo cruel da cruz de Cristo e a noção docetista no islamismo.

Enfim, na tentativa de reconhecer a mediação crística para além da espiritualidade cristã, o que se quer afirmar é que, se as diferentes religiões possibilitam real experiência de Deus, esta acontece na mediação crística. Essa experiência não acontece independente ou paralela à ação de Cristo e do seu Espírito, mas esta ação pode ter nas vivências 
religiosas não cristãs uma forma peculiar de realizar o plano salvífico de Deus. Assim, não se trata de reconhecer apenas um valor subjetivo das espiritualidades não cristãs, mas de afirmar os valores objetivos que nelas se encontram. Afinal, o Espírito de Deus é universalmente presente, antes, durante e depois da encarnação.

\section{Conclusão}

Não há como obter consenso pleno de compreensões e experiências religiosas tão diferentes. E nem se busca esse consenso, uma vez que levaria obrigatoriamente à abdicação de verdades essenciais de cada religião. A questão central que aqui se manifesta para o cristão é como manter a fé na universalidade da ação do Espírito e da graça de Cristo, do plano salvífico de Deus e da unicidade e particularidade da mediação em Cristo (At 4,12; 1Tm 2,3-5; Jo 14,6), sem desmerecer as outras mediações. A resposta se obtém no espírito mais profundo de cada religião. O concílio Vaticano II (1962-1965) ensina que no coração das religiões se manifestam "elementos estimáveis, religiosos e humanos" (GS 92), "coisas verdadeiras e boas" (LG 16), "elementos de verdade e de graça" (AG 9), de "verdade" e de "santidade" (NA 2) que um cristão pode, e deve, estimar. Há possibilidade de sintonia desses elementos com a fé cristã compreendendo-os como semina Verbi (AG 11,15), um "reflexo" da verdade que ilumina toda a humanidade (NA2). Seu patrimônio espiritual é um convite eficaz ao diálogo (NA 2,3: AG 11), não apenas sobre os pontos convergentes, mas também sobre os divergentes. Tais valores coincidem nas grandes tradições religiosas e espirituais da humanidade (DM 26), o que exige dos cristãos uma atitude de atenção e estima para com elas. Assim, é de se valorizar as características e tarefas comuns das religiões, como a conversão ao Transcendente, a solidariedade/amor para com o próximo, o sentido celebrativo do mistério da existência, a gratuidade, a alegria/festa, a esperança, a busca do bem comum (GS 12; 25-26), a dimensão comunitária. É nisso que consiste "o espírito" das religiões, e é nesse espírito que é possível um verdadeiro e fecundo diálogo entre as religiões, que lhes possibilita a cooperação na afirmação de sentido para a vida humana e de toda a criação.

\section{Referências bibliográficas}

ARAÚJO DE OLIVEIRA, M. A Religião na Sociedade Urbana e Pluralista. São Paulo: Paulus, 2013. 
BRETON, S. Unicité et monothéisme, Cerf, 1981.

CARUS, P. The Gospel of Buddha. Nova Delhi: Government of India, 1969.

CASALDALIGA, P.; MARIA VIGIL, J. Espiritualidade da Libertação. Petrópolis: Vozes, 1996.

DHAVAMONY, M. Teologia de las Religiones. San Pablo, 1998.

DUPUIS, J. Verso una teologia cristiana del pluralismo religioso. Brescia: Queriniana, 1997.

ELIADE, M. O Sagrado e o Profano: A essência das religiões. Sãpo Paulo: Martins Fontes, 1995.

FARQUAHR, J. N. Modern Religious Movements in India. New York: The Macmillan e Company, 1918.

MACDERMOTT, R. A. (Org.). Basic Writings of S. Radhakrishnan. New York: Hutton Publisher, 1976.

MURRAY, T. Islam and the Kingdom of God. Princeton, 1933.

PRABHAVANANDA, S. The Sermon on the Mount according to Vedanta. New York: Mentor Book, 1972.

SECRETARIADO PARA OS NÃO CRISTÃOS. A Igreja e as Outras Religiões: Diálogo e Missão.

SUZUKI, D. T. Misticismo Cristiano e Budhista. Roma: Astrolabio Ubaldini Editore, 1971.

TILLICH, P. Teologia Sistemática, vol. 1. São Paulo: Paulinas, 1967. . La mia Ricerca degli Assoluti. Roma: Ubaldini Editore, 1968.

WOLFF, E. A espiritualidade do diálogo inter-religioso: Contribuições na perspectiva cristã. São Paulo: Paulinas, 2016.

E-mail do Autor: elias.wolff@pucpr.br 